\title{
ANALYSIS OF THE POWERTRAIN COMPONENT SIZE OF ELECTRIFIED VEHICLES COMMERCIALLY AVAILABLE ON THE MARKET
}

\author{
Ruzimov Sanjarbek ${ }^{1, *}$, Jamshid Mavlonov ${ }^{1}$, Akmal Mukhitdinov ${ }^{2}$ \\ ${ }^{1}$ Turin Polytechnic University in Tashkent, Tashkent, Uzbekistan \\ ${ }^{2}$ Tashkent State Transport University, Tashkent, Uzbekistan \\ *E-mail of corresponding author: sanjar.ruzimov@polito.uz
}

\section{Resume}

The paper aims to present an analysis of the component sizes of commercially available vehicles with electrified powertrains. The paper provides insight into how the powertrain components (an internal combustion engine, an electric motor and a battery) of mass production electrified vehicles are sized. The data of wide range of mass production electrified vehicles are collected and analyzed. Firstly, the main requirements to performance of a vehicle are described. The power values to meet the main performance requirements are calculated and compared to the real vehicle data. Based on the calculated values of the power requirements the minimum sizes of the powertrain components are derived. The paper highlights how the sizing methodologies, described in the research literature, are implemented in sizing the powertrain of the commercially available electrified vehicles.

\section{Article info}

Received 18 June 2021

Accepted 13 July 2021

Online 12 November 2021

\section{Keywords:}

electrified powertrain, hybrid electric vehicle, battery electric vehicle, component sizing, power requirement, drive cycle

\section{Introduction}

The current trend to reduce vehicle emissions by means of the powertrain electrification results in increased number and models of hybrid electric vehicles (HEV). Some countries are planning to ban partially or fully vehicles with conventional Internal Combustion Engine (ICE) by 2025 and onwards [1-2]. The powertrain hybridization is mainly driven by the fact that it allows substantial fuel consumption reduction [3] and could position as an intermediate step in passing to a fully clean vehicle [4-5]. Therefore, the HEVs will not yet fall into category of vehicles banned in the future, even though they utilize ICE as the main source of motion [2]. The main benefits from hybridization of the conventional ICE powered vehicles are: Stop\&Start feature to avoid engine idling, engine downsizing, operation of the engine at high efficiency region and regeneration of braking energy [3].

Hybrid electric vehicles are classified based on the architecture, on electric motor position and on hybridization ratio [6-7]. Mainly the three HEV architectures are widely used, such as: Series, Parallel and Combined (can be Power-Split or Series-Parallel). Based on the position of the Electric Motor (EM), the HEVs are classified as $\mathrm{P} 0$ to $\mathrm{P} 5$ as shown in Figure 1 [7].

Some of the peculiarities of P0-P5 HEVs can be summarized as follows [6-9]:
P0 - The EM is installed on the accessory belt drive of the engine;

P1 - the EM motor is installed on the output of the engine, before the main clutch;

P2 - the EM is located on the input shaft of the gearbox, after the main clutch (this configuration is considered as pre-transmission $[6,8]$ );

P3 - the EM is mounted on the output of the gearbox (this configuration is considered as post-transmission $[6,8])$;

P4 - the engine and the EM are connected "through the road" [8-9], as they are mounted in different axles;

P5 - in this configuration wheel motors are used [8].

The Plugin HEV (PHEV) is a type of hybrid vehicle that can be recharged from external grid, therefore should have larger battery capacity compared to the HEV [9].

Each of the above mentioned configurations has advantages and disadvantages that must be considered in choosing the either one for implementation on a specific vehicle to be designed.

The selection of configurations depends on number of factors as vehicle class, specific requirements, driving conditions where the vehicle is to be used and others.

Another important step in designing the HEVs is to properly select the powertrain component sizes. The main powertrain components of the HEV are ICE, EM and traction battery pack. 

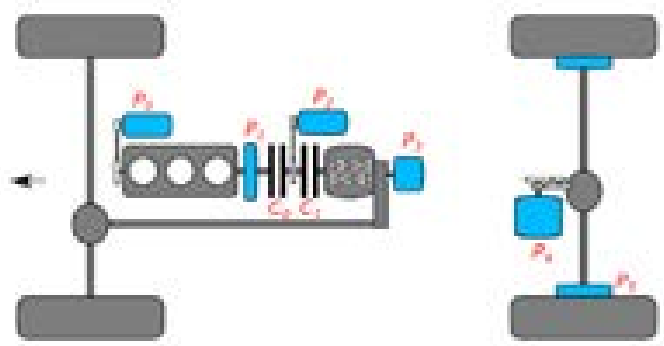

Figure 1 Classification of HEVs based on motor position. P0-P5 positions of the motors and $\mathrm{C}, \mathrm{C} 1$ are positions of the friction clutches

The ICE is the main power source of the conventional vehicles and its size is derived from the vehicle minimum dynamic requirements, while, in HEV the ICE can be used in different modes, but still functions as the main power source. Since the first appearance of HEV at the market, vast variety of the literature has been devoted to sizing of the HEV powertrain components.

In the work of Rahman et al. [10] the engine is sized to produce an average load power, which allows the engine to work at constant loads, avoiding transient operations where it consumes more fuel. In that case, the transient loads during the acceleration or deceleration modes are provided by the electric motor. Size of the electric battery is defined from a consideration to deliver the electric motor peak power and to guarantee a certain electric driving range while staying within the allowed SOC (State of Charge) range of the battery. A Lead Acid battery and the charge sustaining control strategy are considered in the analysis [10].

In further evolution of the work [11], the authors suggest to size the engine and the electric motor power such that they together are able to accelerate the vehicle to $96 \mathrm{~km} \cdot \mathrm{h}^{-1}$ in $10 \mathrm{~s}$. Moreover, the power sources are verified to deliver enough power to drive at a constant speed of $55 \mathrm{mph}\left(\sim 89 \mathrm{~km} \cdot \mathrm{h}^{-1}\right)$ on a $6.5 \%$ grade and at a maximum speed of $100 \mathrm{mph}\left(\sim 161 \mathrm{~km} . \mathrm{h}^{-1}\right)$ on a flat road. Both pre- (this terminology is used [11] to describe the $\mathrm{P} 1$ and $\mathrm{P} 2$ configurations) and posttransmission (is used to describe the P3 configuration) HEV configurations are considered [11]. The battery capacity is defined as a ratio of the maximum electric motor power to $3 \mathrm{~kW}$ power [11]. This might be due to the fact that the single battery module under the consideration supplies $3 \mathrm{~kW}$ and the previous ratio defines the number of parallel battery modules.

The P1 and P2 configurations are studied by Sundstrom et al. in [12-13]. A constant ratio of the total power to vehicle mass equal to $67 \mathrm{~W} / \mathrm{kg}$ is obtained by scaling the engine and electric motor powers, thus varying the hybridization ratio. The constant power to mass ratio allowed to keep the vehicle performance (time to accelerate to $100 \mathrm{~km} \cdot \mathrm{h}^{-1}$ in $11.3 \mathrm{~s}$, maximum speed of $120 \mathrm{~km} \cdot \mathrm{h}^{-1}$ and gradeability) within a similar range in all the considered cases. The Nickel Metal Hydride (NiMH) battery with the maximum power corresponding to the maximum power requirement of the electric motor (accounting all the losses) is considered [13].
Carignano et al. [14] defines the total power of the ICE and the electric motor to meet the required acceleration levels. However, the minimum size of the ICE is limited by constraint that the latter alone should be able to run the vehicle at $120 \mathrm{~km} \cdot \mathrm{h}^{-1}$. Maximum rated power of the electric motor is considered in defining the size of the electric battery [14].

Recently, different companies started to offer hybrid powertrain modules, as one presented by [15], a standalone P4 hybrid powertrain module, which uses $70 \mathrm{~kW}$ continuous (90 kW peak) power motor supplied by $400 \mathrm{~V}$ battery pack. Another solution for the P2 configuration HEVs with $50 \mathrm{~kW}$ continuous power (100 $\mathrm{kW}$ peak power for $30 \mathrm{~s}$ ) and for input torque range of $150-350 \mathrm{Nm}$ from the ICE is declared [15]. These standalone modules require further readjustment of the control strategies while integrated with different engines.

While the above-mentioned literature mainly focuses on the HEVs, Gao and Ehsani [16] discussed a design methodology of the electric motor and the battery size for PHEV. The electric motor is sized to provide the maximum required power in urban driving condition considering the transmission efficiency. The battery capacity is defined to have 40 miles (around $64 \mathrm{~km}$ ) of pure electric traction in urban driving conditions (urban driving part of the FTP75 cycle is used). The battery power is sized to be able to provide the electric motor maximum power. As the latter is defined by the maximum discharge current limitations of the battery, it is expected that this limitation does not take part in the PHEVs, as the battery capacity is large enough.

Murgovski et al. [17] dealt with sizing of a battery for the PHEV bus. Dynamic Programming based optimization method is used to minimize the total costs of ownership that also includes the battery replacement costs due to its degradation. The simulation is performed in a representative driving cycle considering the battery capacity degradation by $20 \%$.

The size of the powertrain components of the PHEV with a hybrid energy storage system (HESS - i.e. combination of super-capacitor and Lithium Polymer battery) are defined by Song et. al [18]. Battery capacity degradation as a function of its temperature and the discharging rate is introduced in this work. The battery pack and super-capacitor capacities are optimized summing the fuel, the electricity and the 
battery degradation costs, using the Pontryagin's minimum principle. The lower bound for the battery size, used in the optimization problem, is selected to satisfy $50 \mathrm{~km}$ of pure electric range at constant speed of $40 \mathrm{~km} \cdot \mathrm{h}^{-1}$.

The analysis of the broad literature on the subject, mainly based on research papers, highlights that the size of the electric motor and the battery largely depend on the performance requirements, the configuration of the hybrid vehicle, the features and the used control strategy. It can be observed, that the size of the ICE and the electric motor are mainly derived from requirements of the vehicle acceleration and the maximum speed performance, while the battery capacity is derived either from the maximum power required from the traction electric motor or from the desired electric drive range.

There are about $200 \mathrm{HEV}$ and PHEV models available on the market, including the ones available only at local markets [19]. Jung [19] analysed 65 models of the HEVs and PHEVs available on the market to find the correlation between the fuel economy, the driving range and the vehicle mass. Zhang et al. [20] attempted to analyse the market development of the PHEVs in United States and China. By analysing the PHEV models available on two markets, they defined the most widespread powertrain architecture, configuration and vehicle categories for each market [20]. However, these works did not consider the powertrain component sizing issues of currently available hybrid powertrains on the market.

Published studies show that there is no study on how the powertrain components of HEVs and PHEVs available on the market are sized. Therefore, this paper attempts to reveal the sizing methodologies of powertrain components of various HEVs and PHEVs by comparing power values and the battery capacities with necessary values to meet the performance requirements. Furthermore, the performance of commercially available Conventional (CONV) and Battery Electric Vehicles $(\mathrm{BEVs})$ and the size of their powertrain components are compared to those of the HEVs and PHEVs. Thus, all the vehicle types with different electrification level, ranging from conventional to pure electric vehicle, can be critically reviewed and compared.

To fulfil that aim, this paper is organized as follows:

The first (previous) section analysed the sizing methodologies of the hybrid powertrain components available in the research literature. The following second section is devoted to description of the theoretical fundamentals of the power and capacity values calculation to meet the main performance requirements. The third section illustrates the data collection, analysis of various powertrain component data and comparison between the computed results of a desired performance. The discussion and conclusions include interpretation of results in terms of the powertrain components' sizing.

\section{Theoretical calculation of vehicle performance}

In this section the main requirements to vehicle performance, the theoretical basis of calculation of the required traction power and the desired battery capacity are presented.

\subsection{Vehicle performance requirements}

The performance requirements that vehicle must meet define the size of the powertrain components. The companies have to follow international, national or internal regulations and goals. Most widely recognized performance goals are listed in Partnership for a New Generation of Vehicles (PNGV), the initiative by United States Government [21-22], which specifies the lower thresholds of vehicle performances. The requirements by PNGV can be summarized as follows [21-22]:

- Minimum acceleration requirement from 0-60 mph $\left(0-96 \mathrm{~km} \cdot \mathrm{h}^{-1}\right)$ in less than $12 \mathrm{~s}$;

- Overtaking manoeuvre 40-60 mph (65-96 km.h $\left.\mathrm{h}^{-1}\right)$ in less than $5.3 \mathrm{~s}$;

- Maximum speed, not less than $85 \mathrm{mph}\left(137 \mathrm{~km} \cdot \mathrm{h}^{-1}\right)$;

- Driving at a constant speed of $55 \mathrm{mph}\left(89 \mathrm{~km} \cdot \mathrm{h}^{-1}\right)$ on a $6.5 \%$ slope;

- Maximum gradeability (required for climbing in parking places).

\subsection{The theory of required power computation}

The power and energy needed to fulfil the abovementioned requirements can be obtained using the quasi-static approach with a backward model [3, 22-24]. The approach can be used for different classes of vehicles by varying their mass.

Below, the theoretical basis of defining the required power in different modes are discussed.

The power $P_{g}$ required to drive the vehicle on a grade with a slope $\alpha_{s}$ at a certain speed $v_{s}$ is calculated as:

$P_{g}=m_{v} \cdot g \cdot v_{v} \cdot \sin \alpha_{g}+m_{v} \cdot g \cdot f_{r} \cdot v_{v}+$

$+\frac{1}{2} \cdot \rho_{a} \cdot c_{x} \cdot A_{f} \cdot v_{v}^{3}$

where $m_{v}$ - vehicle mass, $\mathrm{kg}, f_{r}$ - tyre rolling resistance coefficient, $\rho_{a}$ - air density, kg.m ${ }^{-3}, c_{x}$ - aerodynamic drag coefficient, and $A_{f}$ - vehicle frontal area, $\mathrm{m}^{2}$.

The power $P_{V \operatorname{Vax}}$ required to drive at maximum speed $v_{\max }$ on a flat road, can be calculated as:

$P_{V \max }=m_{v} \cdot g \cdot f_{r} \cdot v_{\max }+\rho_{a} \cdot c_{x} \cdot A_{f} \cdot v_{\max }^{3}$,

where, $v_{\max }$ is the vehicle maximum speed, $\mathrm{m} . \mathrm{s}^{-1}$.

The power $P_{a c c}$ required to accelerate the vehicle from a standstill to $60 \mathrm{mph}$, can be calculated using the 
Table 1 Main vehicle parameters used in the required power and energy calculations

\begin{tabular}{clccc}
\hline$\#$ & Parameter & Nomenclature & Units & Value \\
\hline 1. & Vehicle mass & $m_{v}$ & $k g$ & var \\
2. & Aerodynamic drag coefficient & $c_{x}$ & - & 0.3 \\
3. & Tyre rolling coefficient & $f_{r}$ & - & 0.01 \\
4. & Road grade & $\alpha_{g}$ & $\% .5$ \\
5. & Driving speed on a grade $\alpha_{g}$ & $v_{g}$ & 89 \\
6. & Frontal area & $A_{f}$ & $m^{2}$ & 2 \\
\hline
\end{tabular}

approach proposed by Plotkin et al. [22]:

$$
\begin{aligned}
& P_{a c c}=m_{v} \cdot \frac{v_{f}^{2}}{0.1}\left(\left(\frac{t_{f}+0.1}{t_{f}}\right)^{x}-1\right)+m_{v} \cdot g \cdot f_{r} \cdot v_{f}+ \\
& +\frac{1}{2} \cdot \rho_{a} \cdot c_{x} \cdot A \cdot v_{f}^{3},
\end{aligned}
$$

where $v_{f}$ is the vehicle final speed during the acceleration, $\mathrm{m} . \mathrm{s}^{-1} ; x$ is the exponent, which was selected to be equal to 0.66 (is selected in the range $0.5-0.66$ [22]).

To calculate the energy and power requirements in a homologation driving cycle, the backward simulation approach [3, 24] can be considered, which requires the calculation of traction forces on the driving wheel. In general, the power $P_{\text {wheel }}$ required on the wheels to accelerate and overcome the aerodynamic and road resistances at each time instant is calculated as:

$$
\begin{aligned}
& P_{\text {wheel }}=m_{v} \cdot a_{x} \cdot v_{v}+m_{v} \cdot g \cdot f_{r} \cdot v_{v}+ \\
& +\frac{1}{2} \cdot \rho_{a} \cdot c_{x} \cdot A \cdot v_{v}^{3},
\end{aligned}
$$

where $a_{x}$ is the vehicle longitudinal acceleration, $\mathrm{m} . \mathrm{s}^{-2}$. It is calculated using the speed profile of the driving cycle.

The required power values are calculated using the data shown in Table 1 and carrying the vehicle mass. Obviously, the variation of the vehicle mass leads to change of many vehicle parameters (geometry, aerodynamics, tyre type, etc). However, in the calculation procedure following assumptions are made:

- The aerodynamic drag coefficient is constant regardless the vehicle class and the mass;

- The tyre rolling resistance coefficient is constant and does not depend on vehicle class, the mass and the vehicle speed;

- The vehicle frontal area is constant for all the considered vehicle mass;

- For above parameters the average values of different vehicle class were used.

The size of the battery can be derived from the energy required for motion to perform a certain driving cycle. Based on such a derived value of the energy and the distance traveled during the cycle, the battery size can be calculated knowing the desired electric driving range with one complete charge.

The energy required for motion $E_{\text {wheel }}$ can be obtained by integrating the power needed for traction at wheel level over a time $T$ :
$E_{\text {wheel }}=\int_{0}^{T} P_{\text {wheel }} \cdot d t$

Depending on the operation mode, the energy at wheel level can be divided to traction $\left(E_{\text {trac.wheel }}\right)$ and braking $\left(E_{\text {brake.wheel }}\right)$ energy:

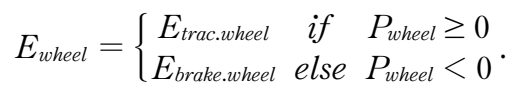

The traction energy required at the battery level $E_{\text {trac.bat }}$ can be computed using the average efficiency of the path (battery $\rightarrow$ electric motor $\rightarrow$ transmission $\rightarrow$ wheels), which consists of the transmission $\eta_{\text {trans }}$, electric motor $\eta_{e m}$ and battery discharging $\eta_{b a t}$ efficiencies.

$E_{\text {trac.bat }}=E_{\text {trac.wheel }} /\left(\eta_{\text {trans }} \cdot \eta_{e m} \cdot \eta_{\text {bat }}\right)$

In the braking phase, the regenerative braking energy $E_{\text {brake.bat }}$ reaches the battery with losses, which again can be accounted with efficiency of the path in the battery charging:

$E_{\text {brake.bat }}=E_{\text {brake.wheel }} \cdot \eta_{\text {trans }} \cdot \eta_{e m} \cdot \eta_{\text {bat }}$.

It is assumed that the efficiencies of the charging and discharging phases are equal. Obviously, the aboveconsidered efficiencies are function of the load and speed. However, for simplification reasons, the calculations carried out here are performed with the average values of efficiencies.

The equivalent energy at the end of the driving cycle $E_{\text {eq.cycle }}$ is the sum of the consumed energy during the traction and one returned to the battery:

$E_{\text {eq.cycle }}=E_{\text {trac.bat }}+E_{\text {brake.bat }}$

where the energy values are in $J\left(E_{\text {eq.cycle. }}\right)$ and can be converted to $\mathrm{kWh}\left(E_{\text {eq.cycle. } . \mathrm{Wh}}\right)$ as:

$E_{\text {eq.cycle.kWh }}=\frac{E_{\text {eq.cycle.J }}}{3.6 e 6}$.

Once the energy $E_{\text {eq.cycle.kWh }}$ over given cycle with distance $S_{\text {cycle }}$ is defined, the energy $E_{\text {eq.kWh }}$ required to drive a certain range $S_{\text {range }}$ can be calculated as follows:

$E_{\text {eq.kWh }}=E_{\text {eq.cycle }-k W h} \cdot \frac{S_{\text {range }}}{S_{\text {cycle }}}$.

For HEVs, the battery size $Q_{k W h}$ (in $\mathrm{kWh}$ ) is derived 


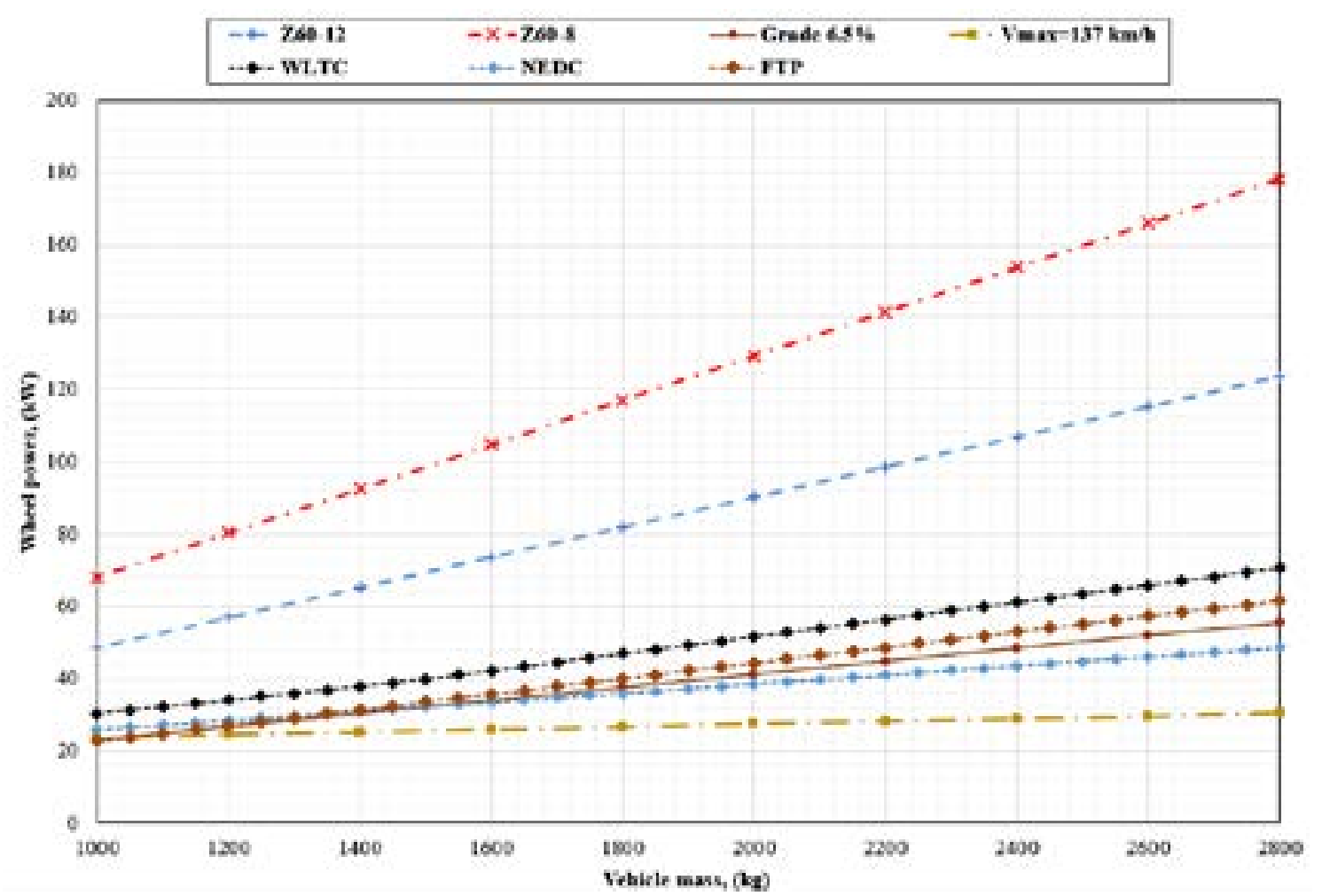

Figure 2 Different power requirements calculated at the wheel level

from the maximum power requirement in traction considering the efficiency of the path and the maximum discharge rate of the battery $C_{\text {rate }}$, as:

$$
Q_{k W h}=\frac{P_{e m \text { max }}}{C_{\text {rate }} \cdot \eta_{e m} \cdot \eta_{b a t}} .
$$

For many lithium based batteries maximum value of $C_{\text {rate }}$ is about 40 for peak currents $(10 \mathrm{~s})$ and 20 for continues current operations [25].

For the PHEVs and the BEVs the battery size can be derived as a ratio of the energy required over the desired driving range to the difference of State of Charge $\triangle S O C$ at the beginning and the end of the travel.

$Q_{k W h}=E_{\text {eq.kWh }} / \Delta S O C$

In general, to avoid overcharging and overheating the upper and lower limits of the lithium based batteries are set to $90 \%$ and $10 \%$, respectively $[6,25]$. Then the useful range of the battery State of Charge $\triangle S O C$ is equal to $80 \%$.

\section{Numerical simulation analysis of the powertrain components sizing}

In this analysis, the specifications of mass production hybrid and electric vehicles are collected from the references [19, 20, 26-29]. The missing data was completed from the manufacturers' websites. The data of the most widespread $41 \mathrm{HEV}, 73 \mathrm{PHEV}$ and 85
BEV models were considered from 21 manufacturers. The list of the manufacturers and the models used in the paper is summarized in [29]. For some of the HEVs and PHEVs, the modifications of the model and different manufacturing year were considered as different data point. Due to lack of the complete data, some of the models were not included. The data for conventional ICE powered vehicles include specifications of around 900 different passenger vehicle models. The models with basic P0 hybrid configuration was not considered, as there are few vehicle models available with complete set of data required in the present analysis.

\subsection{Power requirements}

Based on Equations (1) to (4) the power at wheels needed to satisfy different requirements can be calculated. Figure 2 depicts all the power requirements listed above as a function of the vehicle mass. It is evident that the maximum power requirement corresponds to the one related to acceleration performance, which corresponds to lines Z60-8 and Z60-12. These lines describe the power requirement to accelerate from standstill to $60 \mathrm{mph}$ in 8 and $12 \mathrm{~s}$, respectively. The minimum power requirement corresponds to maximum speed performance (line Vmax $=137 \mathrm{~km} \cdot \mathrm{h}^{-1}$ ). The results of a maximum power required on the vehicle driving wheels on three different driving cycles (NEDC, WLTC and FTP with corresponding lines) show that the WLTC power requirements are the highest. Therefore, for the 

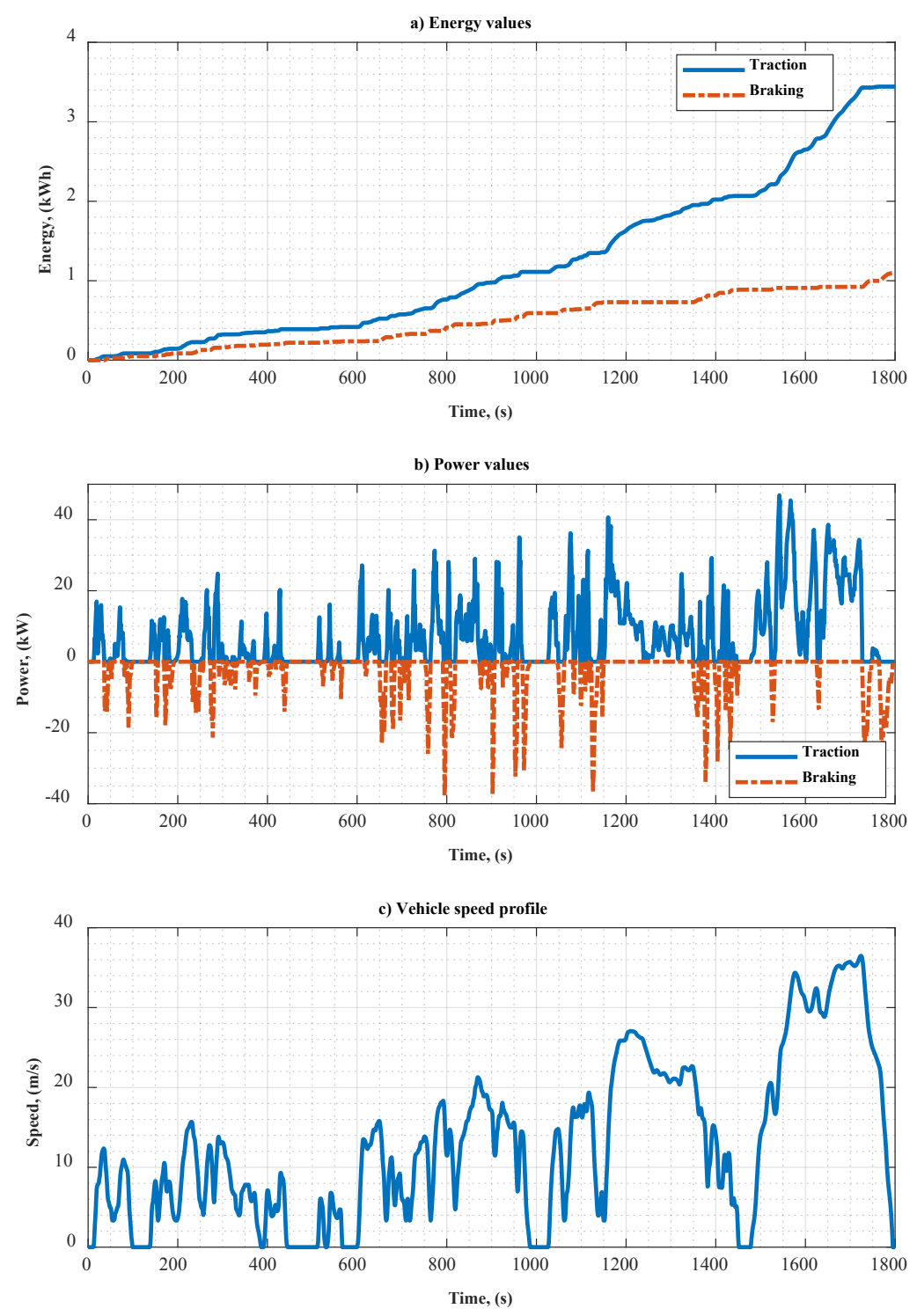

Figure 3 Energy, power values and speed profile at the wheel level on a WLTC

further analysis this line is considered as a maximum power required for motion on a driving cycle. The power required to drive on a grade of $6.5 \%$ slope at a constant speed of $55 \mathrm{mph}$ is in between the power requirements Z60-12 and Vmax. It is nearly equivalent to the power requirement on NEDC driving cycle.

Figure 3 shows the energy, power and speed on the wheel level on the WLTC driving cycle for a vehicle with $1800 \mathrm{~kg}$ mass. Energy required for traction and braking (absolute values are given for latter in Figure 3a) can be used to define the required battery size, while the maximum power values (Figure $3 b$ ) are used to plot Figure 2 by varying the vehicle mass. As can be seen from the Figure 3b, the maximum power over cycle corresponds to the extra-urban part (at time $1543 \mathrm{~s}$ ) of the cycle. This power is higher than the maximum required power needed in urban part of the cycle by $30-50 \%$ (higher value corresponds to lower mass). The Figure 3c shows the vehicle speed profile on a complete
WLTP cycle. The maximum speed of the cycle is about $131 \mathrm{~km} \cdot \mathrm{h}^{-1}$.

\subsection{Internal combustion engine size}

In the conventional vehicle, ICE is solely responsible for traction of the vehicle and therefore must ensure its proper performance. Figure 4 shows the dependence of the $0-100 \mathrm{~km} \cdot \mathrm{h}^{-1}$ acceleration time on the specific power (maximum power to mass ratio) of the traction source. The data points of available HEVs, PHEVs and BEVs are depicted in Figure 4. The dashed line (CALC) represents values of the acceleration time as a function of specific power calculated using Equation (3). The line can be expressed as a power regression function with $\mathrm{R}$-square close to 1 . This equation does not take into account the power requirements of the auxiliaries, therefore it shows the upper bound of the performance at a given specific 


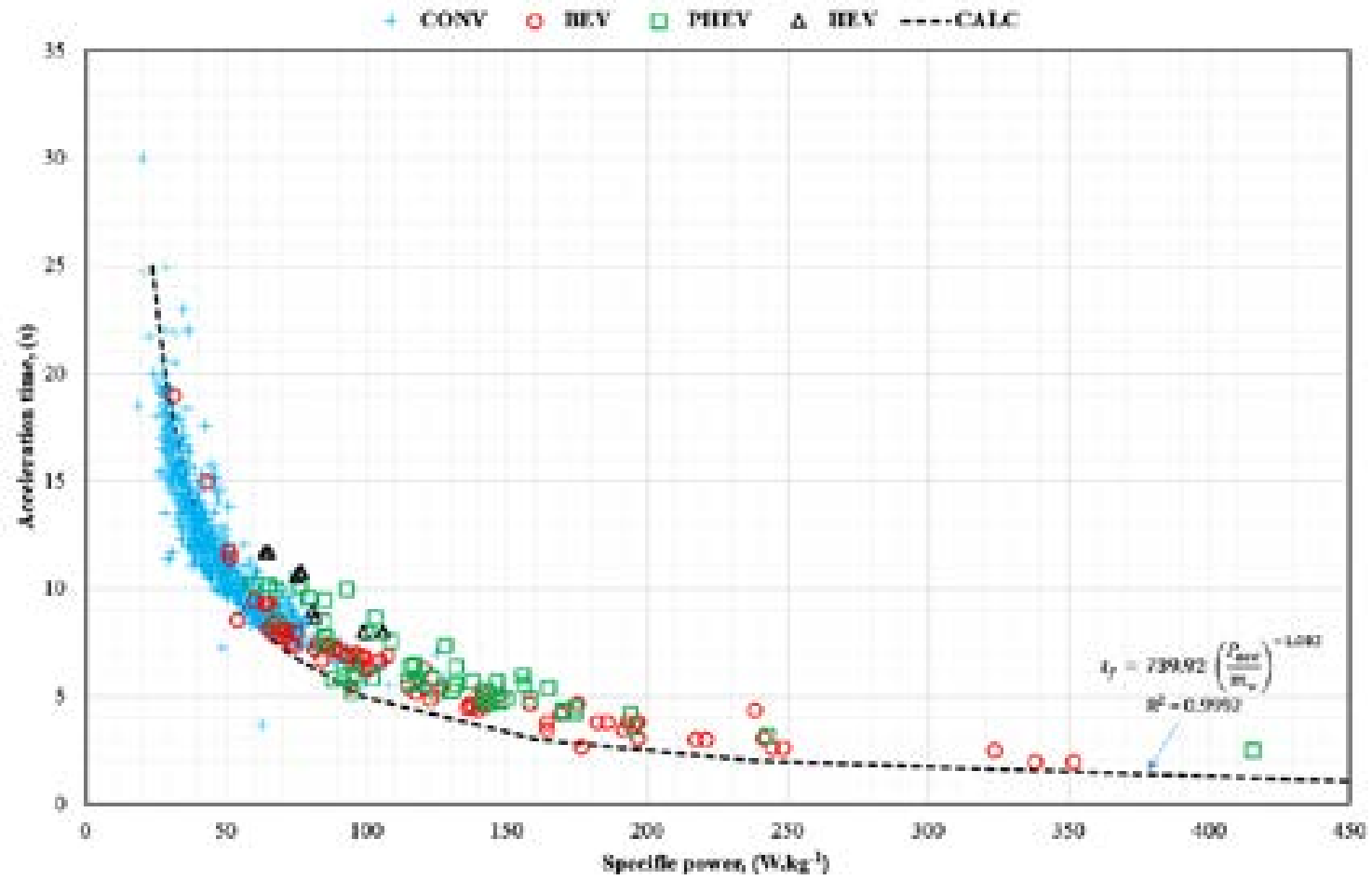

Figure 4 Acceleration time as a function of the traction source specific power for different vehicle types and models

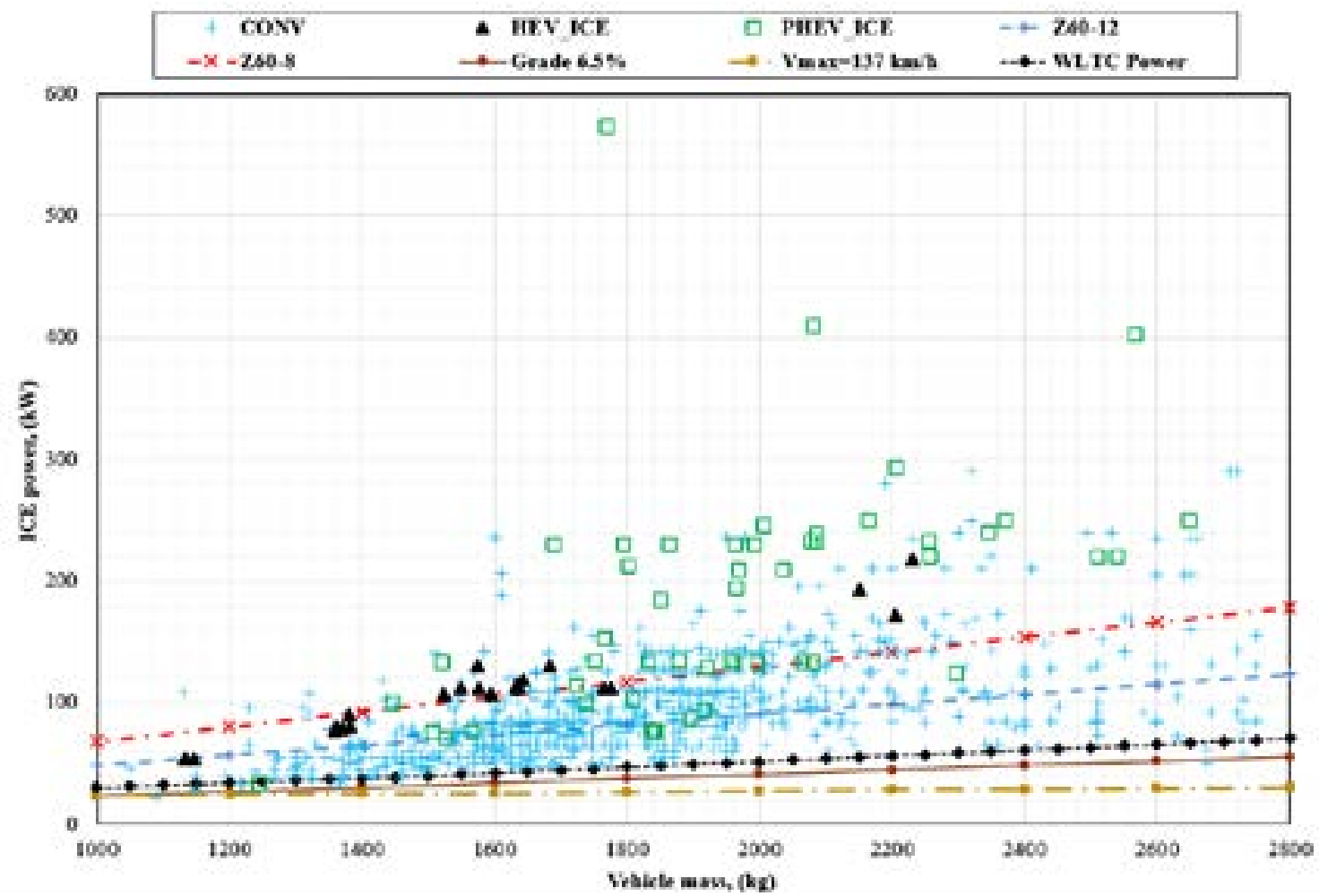

Figure 5 ICE power of Conventional vehicle, HEVs and PHEVs

power. It is evident that for the same specific power, the BEVs provide the highest acceleration performance. Furthermore, Figure 4 shows that the latter equation can be used with good confidence to estimate the power required to accelerate the vehicle.

Figure 5 shows the maximum ICE power points for various vehicle configurations (Conventional, HEV and
PHEV). The power required at the wheel level to fulfill various performance requirements discussed in Figure 2 are also superimposed.

Figure 5 evidences that the ICE maximum power in conventional vehicle is mainly chosen based on a minimum acceleration performance represented by line Z60-12. However, not all the conventional vehicles 


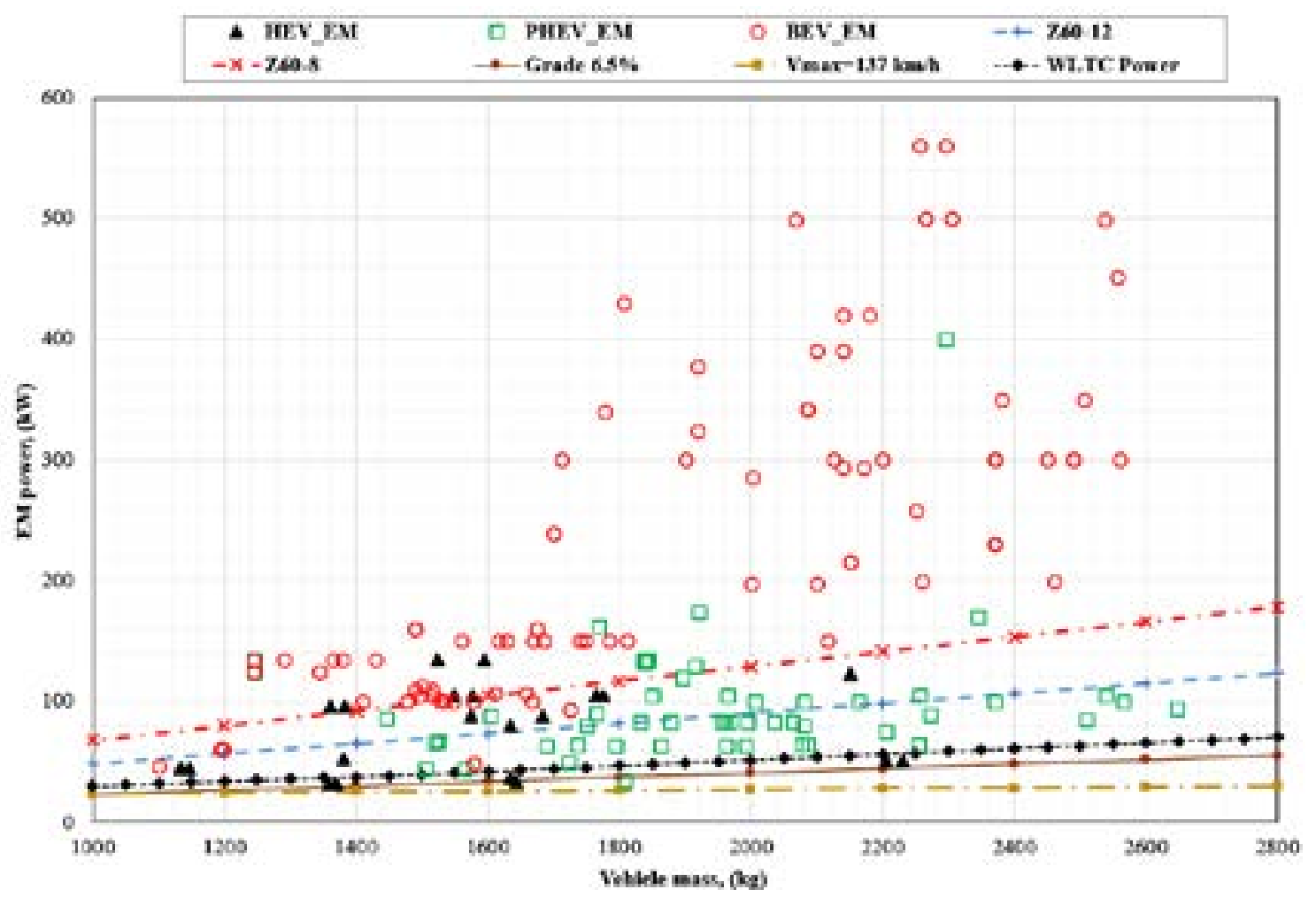

Figure 6. Electric motor peak power for the HEVs, PHEVs and BEVs

can fulfill this requirement. The ICE of the conventional vehicle is at least able to fulfill the maximum power requirement of mild driving cycles as NEDC, which is sufficient for moving in the traffic without causing any potential issues for other participants. This can be seen from the fact that the minimum power of the ICE for all the conventional vehicle models is higher than the power required to drive at $55 \mathrm{mph}$ at $6.5 \%$ grade (Grade $6.5 \%$ line with circle marker).

For the majority of the analyzed HEV and PHEV models, the ICE alone is able to provide minimum acceleration performance. This could be useful in the case when the battery charge is near its lower limits and electric motor cannot provide an assist to the ICE. Furthermore, the higher power of the ICE for hybridized powertrain vehicles can be required to drive the vehicle while charging the battery when latter is depleted. The high power demanding cycle as WLTC can be performed without any limitations using only the ICE.

The ICE of hybrid vehicles can deal with higher power demands compared to the conventional counterparts. The fact highlights that even though downsizing an engine is listed as a potential benefit of the powertrain hybridization that appears rarely practiced in the hybridized vehicles available on the market.

\subsection{Electric motor size}

Figure 6 shows the peak power data points for the electric motor of HEVs, PHEVs and BEVs under consideration. In the electric motors the peak power is usually used for a short time (around 10-60 s) to avoid thermal issues of mainly the batteries [25]. The electric motor continuous power is less than the peak power by around $30-40 \%$ [30]. As it was stated in previous section, the drive cycles have the high power demand in extraurban when compared to urban portion (by $30-50 \%$ for the WLTC). This means that the peak and continuous powers can be used in the analysis for the extra-urban and the urban portions, respectively.

The HEVs (triangle marker) in Figure 6 have the electric motor size that is enough to accomplish the low power demand cycle as NEDC. Furthermore, the urban part of the WLTC can be performed only in the electric mode for a short period, as the thermal issues may arise due to continuous work at peak power.

The electric motor of the majority of the PHEVs (Figure 6, square marker) can accomplish at least the WLTC maximum power demand. That means the urban part of the WLTC can be certainly covered with the electric motor using it in the continuous operation mode. This highlights that the size of electric motors of the PHEVs allow the pure electric vehicle operation if limitation does not come from the batteries. However, not all the PHEV models can fulfill the minimum acceleration performance (line Z60-12) with an electric motor alone.

Obviously, for the BEVs the electric motor is the only traction source. Therefore, as Figure 6 shows, these vehicles with only electric motor are more performant than other vehicle types. The electric motors of the 


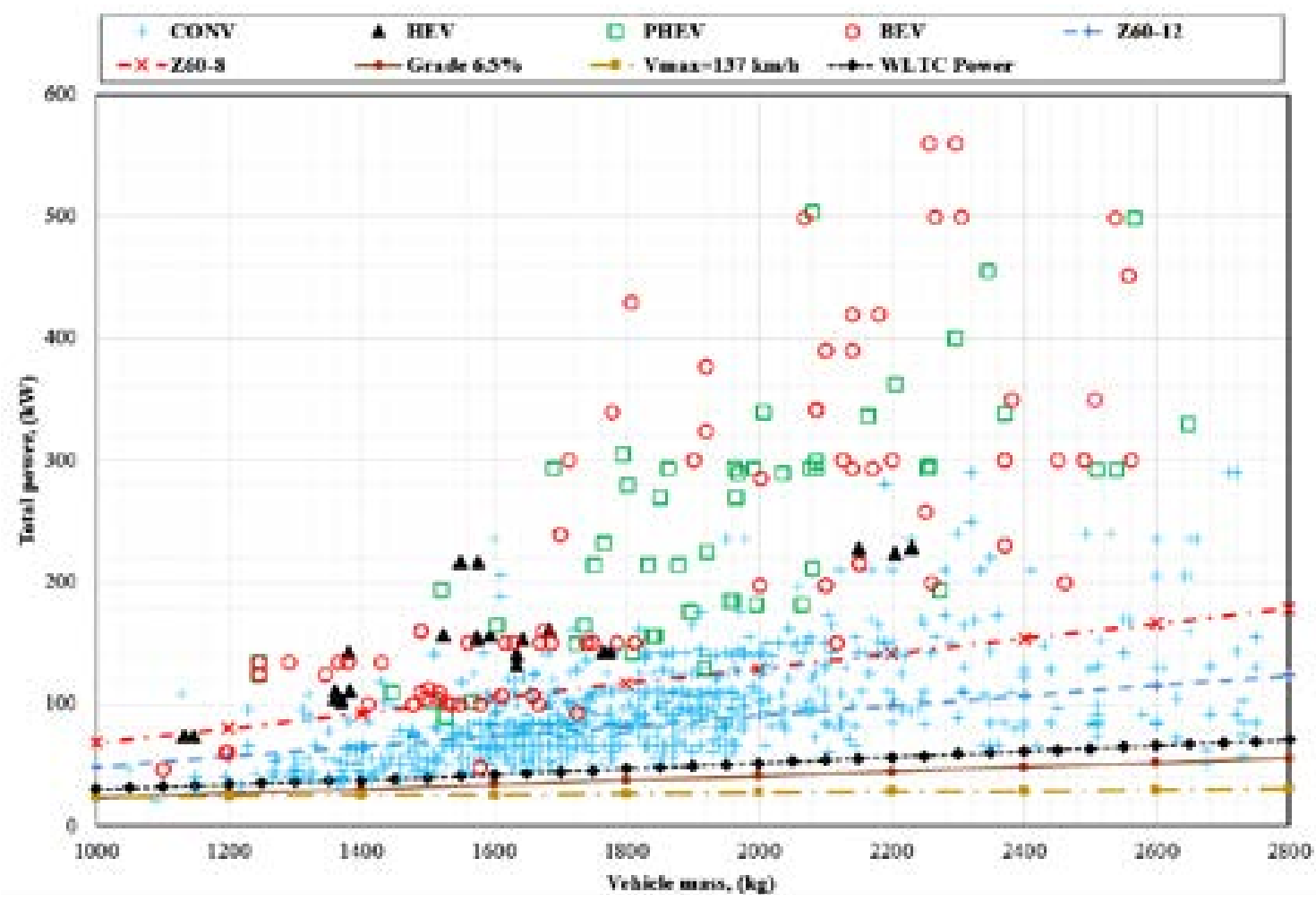

Figure 7 Combined maximum power for the Conventional vehicle, HEVs, PHEVs and BEVs

majority of BEVs on the market can at least provide Z60-12 acceleration performance or better. Figure 4 indicates the performance of the BEVs in terms of shorter acceleration time.

\subsection{Total powertrain size}

Figure 7 shows the combined (ICE+EM) total power for the Conventional vehicles, HEVs, PHEVs and BEVs. As it can be noticed, the power values for the Conventional vehicles and BEVs do not change, as they have one traction source. Instead, for the HEVs and PHEVs the combined power represents the sum of powers available traction sources and can affect substantially the vehicle performance.

The HEVs with total power can have Z60-12 acceleration performance, at minimum, for all the considered models, but mostly fulfills the Z60-8 or higher acceleration performance.

The PHEVs fulfills the aggressive acceleration performance with combined power of ICE and EM. The acceleration levels are equivalent to those of the BEVs. This fact is also evidenced in Figure 4. In addition, it can be noticed that PHEV powertrains are implemented on the vehicle class with curb mass more than $1400 \mathrm{~kg}$.

\subsection{Electric battery size}

The battery capacity for all the considered vehicle configurations and the capacity of the battery required to fulfill a certain pure electric driving range are shown in Figure 8. The energy balance at the end of the driving cycle (WLTC is used) is computed using the average efficiency values for transmission $\eta_{\text {trans }}=0.95$, electric motor $\eta_{e m}=0.9$ and battery discharge $\eta_{\text {bat }}=0.95$.

As it can be noticed, the battery capacity of the HEVs can allow the travel of around $10 \mathrm{~km}$, which corresponds to line "WLTC $10 \mathrm{~km}$ " representing the energy equilibrium in that cycle. The line "Max C-rate" is derived using Equation (12). It shows that nearly all the vehicle categories have the battery size able to deliver the maximum required power on a WLTC cycle. However, the battery thermal limitation might limit the continuous electric traction.

The battery capacities of the PHEVs are able to provide $50 \mathrm{~km}$ electric driving range on a WLTC. The corresponding line "WLTC $50 \mathrm{~km}$ " is calculated using Equations (11) and (13).

As for the BEVs, the only source of traction is the battery, the size of which directly affects the vehicle total driving range. Therefore, the battery size in the $\mathrm{BEVs}$ is mainly derived from the desired driving range and obviously the costs of a vehicle. Models of the BEVs considered in the paper can mainly run more than $200 \mathrm{~km}$ on a single charge on a WLTC representative cycle.

The share of the battery capacity used in various vehicle configurations is presented in Figure 9, where the ranges of the battery capacity have different step size. Between 0 and $5 \mathrm{kWh}$ capacity the step size is equal to $1 \mathrm{kWh}$ to better highlight the region for the 


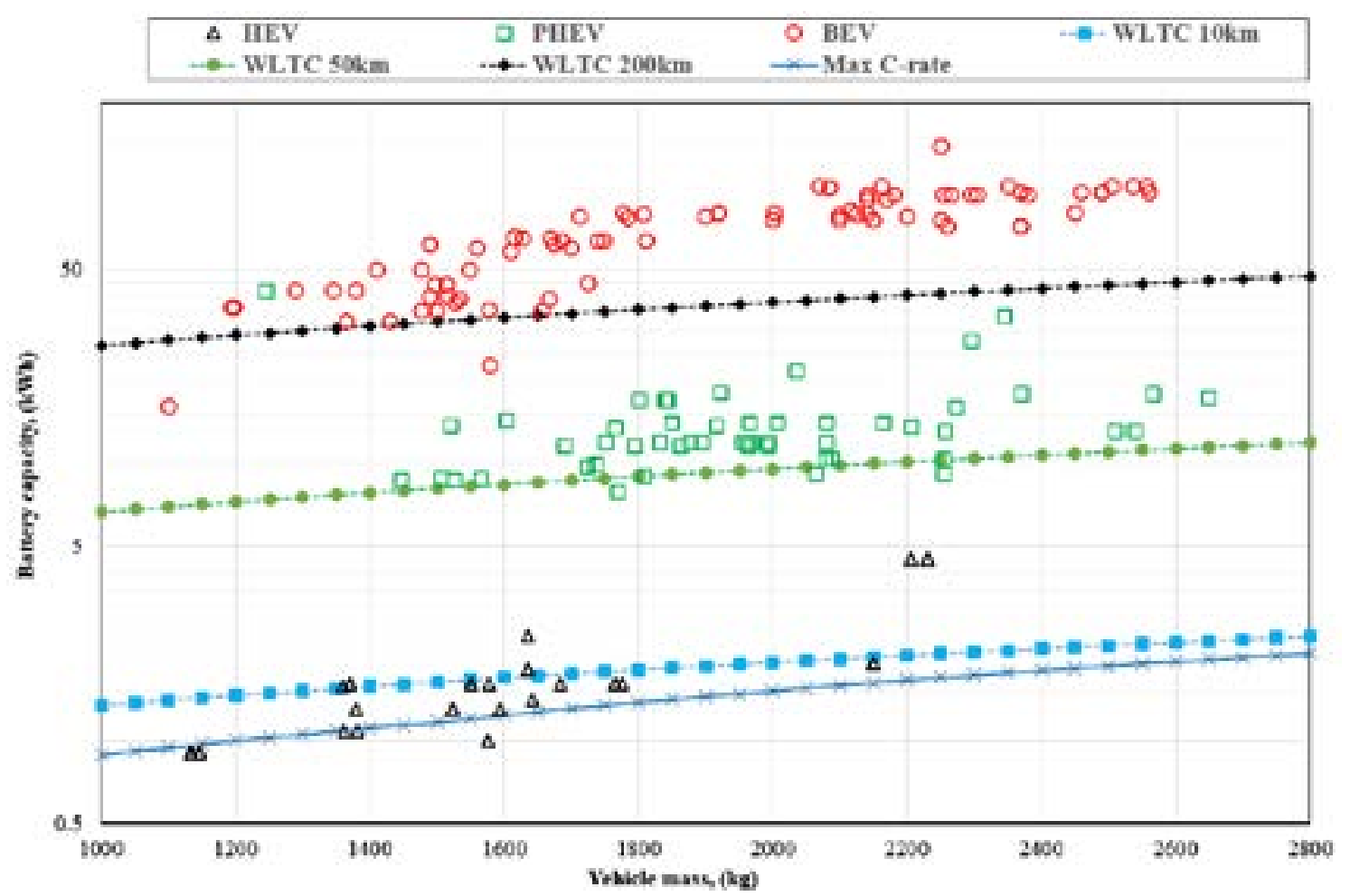

Figure 8 Battery capacity for the HEVs, PHEVs and BEVs

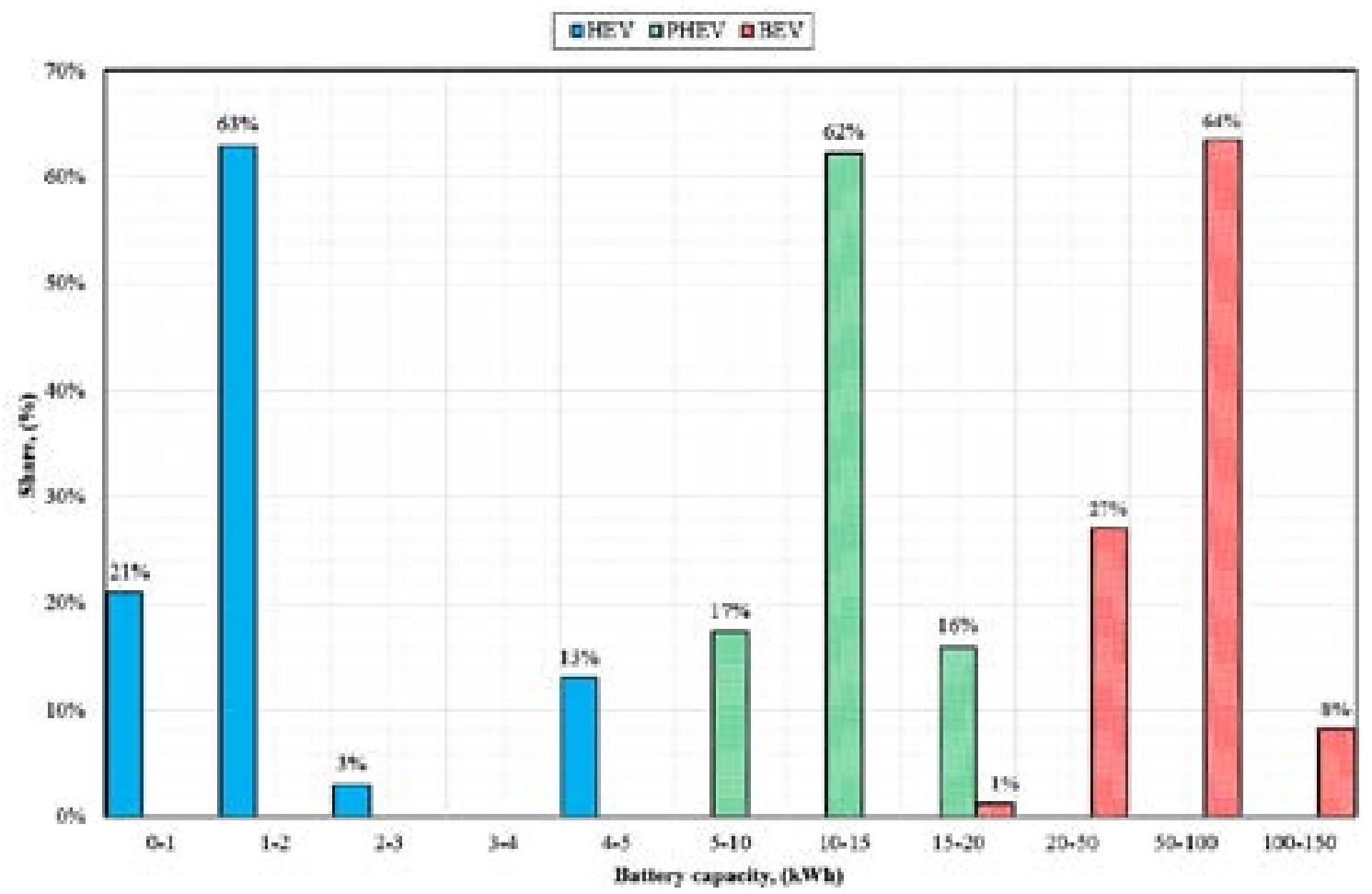

Figure 9 Battery capacity share for the HEVs, PHEVs and BEVs

HEV battery capacities. The range between 5 and 20 $\mathrm{kWh}$ represents mainly the PHEV configurations and the step size for this range is given as $5 \mathrm{kWh}$. For the range above $50 \mathrm{kWh}$ capacity, the step size is also 50 $\mathrm{kWh}$. It can be noticed that the majority of the HEVs in mass production (around 63\%) have battery capacity in the range of 1-2 $\mathrm{kWh}$. Referring to Figure 3, this capacity should be enough to regenerate completely the braking energy over the WLTC cycle. As for the PHEVs the battery capacity is mainly derived from the electric drive range of around $50 \mathrm{~km}$, the majority $(62 \%)$ of considered vehicle battery capacities are in the range of 10-15 kWh.

Around $64 \%$ of the BEVs' models have the battery capacity in the range of $50-100 \mathrm{kWh}$. It is almost 5 to 7 times of one installed on the PHEVs. 


\section{Discussion and conclusions}

The paper provides insight into how the powertrain components of the mass production electrified vehicles are sized. Data of a wide range of mass produced electrified vehicles is collected and sorted. The main PNGV vehicle performance requirements are used to calculate the power values and to compare to the real vehicle data. The results show that the acceleration levels of the PHEVs are equivalent to those of the BEVs. Based on the calculated values of power requirements the minimum sizes of the powertrain components to satisfy such requirements are derived.

The results of this analysis showed that the ICE of hybrid vehicles could deal with higher power demands compared to the conventional counterparts. It emphasizes that the engine downsizing is rarely implemented in hybridized vehicles available on the market.

The electric motors used in the HEVs have a size that is sufficient to accomplish the low power demand cycle or urban part of more power demanding cycles like the WLTC.
The electric motor of the majority of the PHEVs under consideration can fulfill the maximum power demand on the WLTC, which comes from extra-urban part of the cycle. This indicates that the urban part of the WLTC can certainly be driven in pure electric mode if limitation does not come from the batteries.

It is important to note that the considered vehicles have powertrains with excessive power (when total power is considered) with respect to one required to accomplish the real driving requirements.

The battery capacity of the HEVs can allow the travel of about $10 \mathrm{~km}$. The battery capacities of the PHEVs are able to provide $50 \mathrm{~km}$ electric driving range on a WLTC. The BEVs' models considered can drive more than $200 \mathrm{~km}$ on a single charge. The HEVs in mass production (around $63 \%$ ) have battery capacity in the range of 1-2 kWh, while the PHEVs mostly use the battery capacities in the range of $10-15 \mathrm{kWh}$. Around $64 \%$ of the BEVs' models have the battery capacity in the range of $50-100 \mathrm{kWh}$, i.e. almost 5 to 7 times of one installed on the PHEVs.

\section{References}

[1] EU plotting ban on internal combustion engine as of 2025: industry - European Council for an Energy Efficient Economy [online] [accessed 2021-06-14]. 2021. Available from: https://www.eceee.org/all-news/news/eu-plottingban-on-internal-combustion-engine-as-of-2025-industry/

[2] WAPPELHORST, S. The end of the road? An overview of combustion - engine car phase - out announcements across Europe - International Council on Clean Transportation [online] [accessed 2021-06-14]. 2020: Available from: https://theicct.org/sites/default/files/publications/Combustion-engine-phase-out-briefing-may11.2020.pdf

[3] ONORI, S, LORENZO SERRAO, L., RIZZONI, G. Hybrid electric vehicles: energy management strategies. London: Springer, 2016. ISBN: 978-1-4471-6781-5.

[4] Clean Vehicles Directive - European Commission, Mobility and Transport [online] [accessed 2021-06-14]. Available from: https://ec.europa.eu/transport/themes/urban/clean-vehicles-directive_en

[5] SMOKERS, R. T., VERBEEK, M. M., OBDEIJN, C., HILL, N., NORRIS, J., VAN ESSEN, H., KAMPMAN, B., WRIGLEY, S., O'BRIEN, S., TROMPETELER, P. Consideration of alternative approaches to regulating CO2 emissions from light duty road vehicles for the period after 2020 [online] [accessed 2021-06-14]. 2013. Available from:https://ec.europa.eu/clima/sites/clima/files/transport/vehicles/docs/alternatives_en.pdf

[6] EHSANI, M., GAO, Y., LONGO, S., EBRAHIMI, K. Modern electric, hybrid electric, and fuel cell vehicles [online]. 3. ed. Boca Raton: CRC Press, 2018. eISBN 9780429504884. Available from: https://doi.org/10.1201/9780429504884

[7] RAHMEH, H., BONFITTO, A., RUZIMOV, S. Fuzzy logic vs equivalent consumption minimization strategy for energy management in P2 hybrid electric vehicles. In: International Design Engineering Technical Conferences and Computers and Information in Engineering Conference ASME 2020: proceedings. 2020. Available from: https://doi.org/10.1115/DETC2020-22431

[8] eMobility is our future - MAGNA [online] [accessed 2021-05-15]. Available from: http://electrification.magna.com/ powertrain-electrification/

[9] CHEN, M. Y., YANG, K., SUN, Y. Z., CHENG, J. H. An energy management strategy for through-the-road type plug-in hybrid electric vehicles. SAE International Journal of Alternative Powertrains [online]. 2019, 8(1), p. 61-75. ISSN 2167-4191, eISSN 2167-4205. Available from: https://doi.org/10.4271/08-08-01-0004

[10] RAHMAN, Z., BUTLER, K., EHSANI, M. A study of design issues on electrically peaking hybrid electric vehicle for diverse urban driving patterns. SAE Technical Paper [online]. 1999, 1999-01-1151. ISSN 0148-7191, eISSN 2688-3627. Available from: https://doi.org/10.4271/1999-01-1151

[11] RAHMAN, Z., BUTLER, K., EHSANI, M. A comparison study between two parallel hybrid control concepts. SAE Technical Paper [online]. 2000, 2000-01-0994. ISSN 0148-7191, eISSN 2688-3627. Available from: https://doi.org/10.4271/2000-01-0994 
[12] SUNDSTROM, O., GUZZELLA, L., SOLTIC, P. Optimal hybridization in two parallel hybrid electric vehicles using dynamic programming. IFAC Proceedings Volumes [online]. 2008, 41(2), p. 4642-4647. ISSN 1474-6670. Available from: https://doi.org/10.3182/20080706-5-KR-1001.00781

[13] SUNDSTROM, O., GUZZELLA, L., SOLTIC, P. Torque-assist hybrid electric powertrain sizing: from optimal control towards a sizing law. IEEE Transactions on Control Systems Technology [online]. 2009, 18(4), p. 837-849. ISSN 1063-6536, eISSN 1558-0865. Available from: https://doi.org/10.1109/TCST.2009.2030173

[14] CARIGNANO, M. G., NIGRO, N. M., JUNCO, S. Hybridization effect on fuel consumption and optimal sizing of components for hybrid electric vehicles. In: Integrated Modeling and Analysis in Applied Control and Automation IMAACA-I3M: proceedings. 2015.

[15] Optimized electromotive transmission solutions for various applications by FEV - FEV Group GmbH [online] [accessed 2021-06-15]. Available from: http://magazine.fev.com/en/electronic-drive-unit/

[16] GAO, Y., EHSANI, M. Design and control methodology of plug-in hybrid electric vehicles. IEEE Transactions on Industrial Electronics [online]. 2009, 57(2), p. 633-640. ISSN 0278-0046. Available from: https://doi.org/10.1109/ TIE.2009.2027918

[17] MURGOVSKI, N., JOHANNESSON, L. M., EGARDT, B. Optimal battery dimensioning and control of a CVT PHEV powertrain. IEEE Transactions on Vehicular Technology [online]. 2013, 63(5), p. 2151-2161. ISSN 00189545, eISSN 1939-9359. Available from: https://doi.org/10.1109/TVT.2013.2290601

[18] SONG, Z., ZHANG, X., LI, J., HOFMANN, H., OUYANG, M., DU, J. Component sizing optimization of plug-in hybrid electric vehicles with the hybrid energy storage system. Energy [online]. 2018, 144, p. 393-403. ISSN 0360-5442. Available from: https://doi.org/10.1016/j.energy.2017.12.009

[19] JUNG, H. Fuel economy of plug-in hybrid electric and hybrid electric vehicles: effects of vehicle weight hybridization ratio and ambient temperature. World Electric Vehicle Journal [online]. 2020, 11(2), 31. eISSN 2032-6653. Available from: https://doi.org/10.3390/wevj11020031

[20] ZHANG, B., YANG, F., TENG, L., OUYANG, M., GUO, K., LI, W., DU, J. Comparative analysis of technical route and market development for light-duty PHEV in China and the US. Energies [online]. 2019, 12(19), 3753. eISSN 1996-1073. Available from: https://doi.org/10.3390/en12193753

[21] CHALK, S. G., PATIL, P. G., VENKATESWARAN, S. R. The new generation of vehicles: market opportunities for fuel cells. Journal of Power Sources [online]. 1996, 61(1-2), p. 7-13. ISSN 0378-7753. Available from: https://doi.org/10.1016/S0378-7753(96)02332-4

[22] PLOTKIN, S., SANTINI, D., VYAS, A., ANDERSON, J., WANG, M., BHARATHAN, D., HE, J. Hybrid electric vehicle technology assessment: methodology, analytical issues, and interim results - U.S. Department of Energy Office of Scientific and Technical Information [online]. 2002. Available from: https://doi.org/10.2172/807353

[23] GENTA, G. Motor vehicle dynamics: modeling and simulation. Singapore: World Scientific, 1997. ISBN: 978-981-02-2911-5.

[24] GUZZELLA, L., SCIARRETTA, S. Vehicle propulsion systems: introduction to modeling and optimization. Berlin: Springer-Verlag Berlin Heidelberg, 2007. ISBN 978-3-642-35913-2.

[25] 48V lithium-ion battery - 8Ah - A123 Systems [online] [accessed 2021-06-16]. Available from: http://www.a123systems.com/wp-content/uploads/48V-Battery-Flier_2016.pdf

[26] U.S. Department of Energy - Energy Efficiency and Renewable Energy [online] [accessed 2021-06-16]. Available from: https://www.fueleconomy.gov/

[27] Fuel consumption guide, CO2 emissions and electricity consumption of new passenger car models in German market / Leitfaden uber den Kraftstoffverbrauch, die CO2-Emissionen und den Stromverbrauch aller neuen Personenkraftwagenmodelle, die in Deutschland zum erkauf angeboten werden (in German) [online] [accessed 2021-06-16]. Available from: https://www.datgroup.com/leitfaden/LeitfadenCO2.pdf

[28] Availability of hybrid and plug-in electric vehicles - U.S. Department of Energy - Energy Efficiency and Renewable Energy [online] [accessed 2021-06-16]. Available from: https://afdc.energy.gov/vehicles/electric_availability.html

[29] KANE, M. Compare electric cars: EV range, specs, pricing and more - INSIDEEvs [online] [accessed 2021-06-16]. Available from: https://insideevs.com/reviews/344001/compare-evs/

[30] CAI, W. Comparison and review of electric machines for integrated starter alternator applications. In: IEEE 39th IAS Annual Meeting Industry Applications Conference: proceedings [online]. 2004. ISSN 0197-2618, ISBN 0-7803-8486-5. Available from: https://doi.org/10.1109/IAS.2004.1348437 
List of abbreviations

\begin{tabular}{ll}
\hline Abbreviation & Meaning/phrase \\
\hline BEV & Battery Electric Vehicle \\
CONV & Conventional Vehicle \\
EM & Electric Motor \\
FTP & Federal Test Procedure \\
HESS & Hybrid Energy Storage System \\
HEV & Hybrid Electric Vehicle \\
ICE & Internal Combustion Engine \\
NEDC & New European Driving Cycle \\
NiMH & Nickel Metal Hydride \\
PHEV & Plugin Hybrid Electric Vehicle \\
PNGV & Partnership for a New Generation of Vehicles \\
SOC & State of Charge \\
WLTC & The Worldwide harmonized Light vehicles Test Cycles \\
Z60-8 & Time to accelerate to a specific speed (60 mph in $8 \mathrm{~s})$ \\
Z60-12 & Time to accelerate to a specific speed $(60$ mph in $12 \mathrm{~s})$ \\
\hline
\end{tabular}

